\title{
Avoiding Weight Gain in Cardiometabolic Disease: A Systematic Review
}

\author{
Nisa M. Maruthur, ${ }^{1,2,3}$ Kimberly Gudzune, ${ }^{1,2}$ Susan Hutfless, ${ }^{4}$ \\ Oluwakemi A. Fawole, ${ }^{1}$ Renee F. Wilson, ${ }^{5}$ Brandyn D. Lau, ${ }^{6,7,8}$ Cheryl A. M. Anderson, ${ }^{2,3,9}$ \\ Sara N. Bleich, ${ }^{5}$ and Jodi Segal ${ }^{1,5}$
}

${ }^{1}$ Division of General Internal Medicine, Johns Hopkins University School of Medicine, Baltimore, MD 21287, USA

${ }^{2}$ Welch Center for Prevention, Epidemiology, and Clinical Research, Baltimore, MD 21287, USA

${ }^{3}$ Department of Epidemiology, Johns Hopkins University School of Medicine, Baltimore, MD 21287, USA

${ }^{4}$ Division of Gastroenterology, Johns Hopkins University School of Medicine, Baltimore, MD 21287, USA

${ }^{5}$ Department of Health Policy and Management, Johns Hopkins University Bloomberg School of Public Health, Baltimore, MD 21287, USA

${ }^{6}$ Division of Acute Surgery, Department of Surgery, Johns Hopkins University School of Medicine, Baltimore, MD 21287, USA

${ }^{7}$ Division of Health Sciences Informatics, Johns Hopkins University School of Medicine, Baltimore, MD 21287, USA

${ }^{8}$ Armstrong Institute for Patient Safety and Quality, Johns Hopkins Medicine, Baltimore, MD 21287, USA

${ }^{9}$ Department of Family and Preventive Medicine, University of California at San Diego, San Diego, CA 92093, USA

Correspondence should be addressed to Nisa M. Maruthur; maruthur@jhmi.edu

Received 22 November 2013; Revised 3 June 2014; Accepted 16 October 2014; Published 28 December 2014

Academic Editor: Aimin Xu

Copyright (C) 2014 Nisa M. Maruthur et al. This is an open access article distributed under the Creative Commons Attribution License, which permits unrestricted use, distribution, and reproduction in any medium, provided the original work is properly cited.

Patients with cardiometabolic disease are at higher risk for obesity-related adverse effects. Even without weight loss, weight maintenance may be beneficial. We performed a systematic review to identify the effect of nonweight loss-focused lifestyle interventions in adults with cardiometabolic disease. We searched MEDLINE, Embase, and the Cochrane Central Register of Controlled Trials to identify comparative studies of lifestyle interventions (self-management, diet, exercise, or their combination) without a weight loss focus in adults with or at risk for diabetes and cardiovascular disease. Weight, BMI, and waist circumference at $\geq 12$ months were the primary outcomes. Of 24,870 citations, we included 12 trials (self-management, $n=2$; diet, $n=2$; exercise, $n=2$; combination, $n=6$ ) studying 4,206 participants. Self-management plus physical activity \pm diet versus minimal/no intervention avoided meaningful weight $(-0.65$ to $-1.3 \mathrm{~kg})$ and BMI $\left(-0.4\right.$ to $\left.-0.7 \mathrm{~kg} / \mathrm{m}^{2}\right)$ increases. Self-management and/or physical activity prevented meaningful waist circumference increases versus control $(-2$ to $-4 \mathrm{~cm})$. In patients with cardiometabolic disease, self-management plus exercise may prevent weight and BMI increases and self-management and/or exercise may prevent waist circumference increases versus minimal/no intervention. Future studies should confirm these findings and evaluate additional risk factors and clinical outcomes.

\section{Introduction}

Patients with or at risk for diabetes and cardiovascular disease (CVD) are at particular risk for adverse effects of obesity. Obesity increases blood pressure [1] and causes insulin resistance [2] both of which contribute to development of hypertension [3], CVD [4-6], diabetes [7], and their complications including congestive heart failure, recurrent CVD events and death $[4,6]$, diabetic nephropathy, and diabetic retinopathy [8]. Most lifestyle interventions addressing weight in these populations focus on weight loss or maintenance of weight loss [9-11]. These weight loss interventions tend to be quite intensive to produce modest weight reductions but typically result in improved outcomes downstream of weight including reductions in diabetes risk, abnormal glucose homeostasis, low density lipoprotein (LDL) cholesterol, and blood pressure 
[9-12]. In contrast, weight neutral interventions may aim to prevent weight gain or emphasize lifestyle changes to maintain current weight. Trials have demonstrated that weight neutral interventions can improve metabolic risk factors, but they are typically brief [13]. Adults gain one-half kilogram per year on average [14], and the effect of avoiding this weight gain over time, especially in high-cardiometabolic risk populations, remains unclear.

Therefore, we performed a systematic review to determine the comparative effectiveness of self-management, diet, and physical activity interventions without a weight loss focus compared with another lifestyle intervention or usual care on weight, cardiometabolic risk factors, and clinical outcomes in adults with or at risk for diabetes or CVD.

\section{Materials and Methods}

The protocol for this study can be found at (http://effectivehealthcare.ahrq.gov/index.cfm/search-for-guides-reviewsand - reports $/$ ? productid $=824$ \& pageaction $=$ displayproduct $)$ and is based on the Agency for Healthcare Research and Quality (AHRQ) Methods Guide for Effectiveness and Comparative Effectiveness Reviews (http://www.effectivehealthcare.ahrq.gov/methods_guide.cfm). The current study is part of a Comparative Effectiveness Review requested by AHRQ on weight maintenance in adults [15]. This study focuses on weight neutral lifestyle interventions in populations with or at risk for diabetes or CVD.

2.1. Eligibility Criteria. We included full text articles with original data that compared the effects of weight neutral (i.e., those not focusing on weight loss as a goal of the study) lifestyle interventions relative to a concurrent comparison group (active intervention listed below, minimal intervention, or usual care) on weight, BMI, or waist circumference in adults with diabetes, CVD, or risk factors for these conditions (e.g., elevated blood sugar, dyslipidemia, and hypertension). Included studies could evaluate interventions for weight maintenance or avoidance of weight gain; if the weight-related focus of a study was unclear, we contacted authors as described below. Active interventions of interest were self-management, diet, physical activity interventions, or combinations of these in which weight loss was not a specified goal. We considered the following to be elements of self-management: problem-solving, addressing barriers, selfmonitoring, goal-setting, and individualized counseling. We excluded studies of weight loss; weight maintenance after weight loss; pregnant women; patients at risk for weight loss (e.g., patients on dialysis); smoking cessation; biologic determinants of weight (e.g., genes); supplements; and interventions lasting $<12$ months. We excluded studies not reporting quantitative results for weight, BMI, or waist circumference. Additional outcomes were adverse events, adherence, and quality of life. Clinical outcomes included mortality, cancer, cardiovascular disease, subfertility, diabetes, degenerative joint disease, liver disease, and quality of life. Although it is not included in the full evidence report [15], for this paper, we also included hemoglobin Alc (HbAlc), blood pressure, low density lipoprotein (LDL) cholesterol, and high density lipoprotein (HDL) cholesterol. We included observational studies that accounted for confounding and losses to followup in the weight analyses.

2.2. Search. We searched the MEDLINE, Embase, and Cochrane Central Register of Controlled Trials electronic databases through June 2012. We searched the references of included articles and key review articles. We searched ClinicalTrials.gov on June 19, 2012. The MEDLINE search strategy is available in the full report.

2.3. Study Selection. Two investigators reviewed titles, abstracts, and full text articles independently. All titles included by one investigator were reviewed at the abstract level. Two investigators agreed on inclusion during the abstract and full text reviews. Disagreements were resolved through consensus. All articles meeting eligibility criteria were included in the systematic review. When an article did not explicitly state a weight-related goal, we contacted the authors for clarification. We excluded studies if the authors responded that weight loss was an intended outcome and included any articles for which we did not receive an author response. We also excluded any articles not reporting on our primary outcomes, weight, BMI, and waist circumference, in their abstracts as we assumed that those weight outcomes were not important measures in those studies.

2.4. Data Collection. Data were extracted from articles by two investigators sequentially using forms created in the web-based software, DistillerSR (Evidence Partners, Ottawa, Ontario, Canada). We piloted all forms prior to use. A senior reviewer reviewed the initial abstraction performed by a junior investigator. Disagreements were resolved through consensus. Data on study design, interventions, study population characteristics, outcomes, timing, and setting were abstracted. We collected data on 12-month outcomes and the longest time point available in each study.

2.5. Risk of Bias. We evaluated the risk of bias in individual studies using the Downs and Black criteria [31] and focused on reporting and internal validity across studies to assign a rating of "low," "moderate," or "high" risk of bias for the weight outcomes. Randomized, controlled trials (RCTs) were considered to be at "low" risk of bias but were downgraded to "moderate" if they did not report masking of outcome assessors for the weight outcomes. Other concerns could also result in downgrading of the risk of bias.

We based our rating of the strength of evidence for each outcome on the risk of bias, consistency ("consistent" if most effect estimates were in the same direction), directness, ("direct" based on explicitly stated a goal of weight gain prevention), and precision ("precise" if statistically significant $(P<0.05))$ of the studies evaluating that outcome [32]. For adherence, we considered the evidence to be precise if the study included $>400$ participants. We rated the strength of evidence as "high," "moderate," "low," or "insufficient (no evidence)" based on confidence in the effect estimate as previously described [32]. 
2.6. Synthesis of Results. We did not perform meta-analyses because of the heterogeneity of study interventions. We defined thresholds for clinically meaningful between-group differences over 12 months based on expected increases in anthropometric measures and effects of lifestyle interventions on biochemical measures as follows: weight, $0.5 \mathrm{~kg}$ [14]; BMI, $0.2 \mathrm{~kg} / \mathrm{m}^{2}$ (based on a one-half $\mathrm{kg}$ change with initial BMI $27 \mathrm{~kg} / \mathrm{m}^{2}$ ); waist circumference, $1 \mathrm{~cm}$ [33]; blood pressure, $5 \mathrm{mmHg}$; HbAlc, 0.7\% [34]; HDL cholesterol, $5 \mathrm{mg} / \mathrm{dL}$ [35]; and LDL cholesterol, $10 \mathrm{mg} / \mathrm{dL}$ [13].

\section{Results}

3.1. Search Results. Of 24,870 electronic citations, 9,041 abstracts, and 1,426 full text articles, we identified 11 RCTs [17-29] and one nonrandomized clinical trial [16] evaluating the effect of self-management, dietary, or physical activity interventions without a weight loss focus in persons with or at risk for diabetes and/or CVD (Figure 1). We did not identify observational studies meeting our inclusion criteria.

3.2. Study Characteristics. Study characteristics are provided in Table 1. Weight maintenance was a stated goal in one study [16]; the other studies emphasized lifestyle changes and did not explicitly state weight loss as a goal [17-29]. Six studies were conducted in patients with diabetes $[16,20,21,23,26$, 28]. The other six studies included participants with risk factors for diabetes or CVD such as dyslipidemia, elevated blood pressure, and elevated HbAlc [17-19, 22, 24, 25, 27, 29]. Four of these excluded patients with CVD $[17,18,22,24,25$, 27], and three excluded patients with diabetes [17, 18, 22, 27]. Most trials were conducted in Europe [17, 18, 20, 21, 24, 25, 29] and the United States $[16,22,28]$ and at a single study site $[16-21,26,27,29]$. Most studies did not report on years of recruitment $[16,20,21,23-28]$. Participants were recruited from a clinical setting in seven studies [16, 20, 21, 23-26, 28] and the others from a cohort study $[17,18]$, insurance plan [19], and diabetes screening program [29]; two studies did not report on recruitment setting $[22,27]$. Follow-up ranged from one to two years [16-18, 23, 26, 28].

The 12 trials enrolled 4,206 participants (see Table S1 in Supplementary Material available online at http://dx.doi .org/10.1155/2014/358919). Women comprised 31 to $100 \%$ of participants in the nine studies reporting on sex [19-30]. Mean age ranged from 57 to 68 years in nine trials [16, 19$21,23-26,28-30$ ] and was reported by sex in another (57 years for women and 48 years for men) [27]. All participants were Latina in one trial [28]; twenty-six percent Asian or Pacific Islander in another [29]; and 17\% black in another [22]. Nine trials did not report on race/ethnicity [16-21, 23$27,30]$. Education level varied across studies with $65 \%$ of participants reporting some postsecondary education in one study [23] and less than one-third of participants reporting this in others $[24,25,28,30]$. One study excluded current smokers [26], and current smoking ranged from 10 to $20 \%$ in three studies [24, 25, 28-30].

We identified two trials of self-management interventions $[20,23]$; two of dietary interventions $[16,24,25,30]$; two of physical activity interventions [17, 18, 29]; and six of combinations of these (Table 2) $[19,21,22,26,28]$.

3.3. Risk of Bias. Major issues affecting internal validity were lack of, or lack of reporting on, masking of outcome assessors, prespecified analyses, allocation concealment, and losses to follow-up (Table S2).

We found low strength of evidence for all outcomes for which there was at least one study (Table S3). The risk of bias for each outcome was moderate or high for all outcomes. Frequently, consistency could not be evaluated because there was only a single study. Evidence was indirect because only one study cited weight maintenance as a goal of the study; the other studies did not specify their goal regarding weight, and their intent was clarified by contacting authors as described in the Methods section. Most evidence was imprecise based on small sample size or lack of reporting on variability.

\subsection{Synthesis of Results}

Weight, BMI, and Waist Circumference. Study results are provided in Tables 3 and 4 and S4 and Figures 2, 3, and 4.

A self-management intervention based on goal-setting and problem-solving for diet and physical activity prevented an increase in BMI of $1.76 \mathrm{~kg} / \mathrm{m}^{2}$ at 12 months compared with usual care [20]. A study of an intensive diabetes selfmanagement intervention decreased BMI by $0.4 \mathrm{~kg} / \mathrm{m}^{2}$ at 12 months compared to the same intervention combined with a physical activity supplement [23]. The statistical significance of findings from these studies was not reported $[20,23]$. These studies reported meaningful (between-group differences, -2 to $-3.9 \mathrm{~cm}$ ), but not statistically significant, relative effects of their interventions on waist circumference [20,23].

In the PREvencion con DIeta MEDiterranea (PREDIMED) Study, two Mediterranean diet interventions did not prevent increases in weight at 36 months [24], BMI at 12 months [30], or waist circumference at 36 months [25] relative to a minimal intervention. The American Diabetes Association diet prevented weight gain relative to a standard diabetic diet at 12 but not 24 months in another study $[16,30]$.

Walking interventions did not prevent weight or BMI increases at 12 months relative to printed information in the Prediabetes Risk Education and Physical Activity Recommendation and Encouragement (PREPARE) study [29]. In the Oslo Diet and Exercise Study (ODES), relative to control, the endurance exercise intervention prevented meaningful increases (between-group difference $(95 \% \mathrm{CI}))$ in weight $(-2$ $(-3.4$ to -0.6$) \mathrm{kg})$ [17], BMI $\left(-0.7(-0.76\right.$ to -0.64$\left.) \mathrm{kg} / \mathrm{m}^{2}\right)$ [18], and waist circumference $(-2.8(-4.2$ to 1.4$) \mathrm{cm})$ [17] at 12 months.

The combination of self-management with physical activity prevented meaningful increases in weight $(-0.65$ to $-1.26 \mathrm{~kg}$ ) and BMI (between-group differences range, -0.4 to $-0.7 \mathrm{~kg} / \mathrm{m}^{2}$ ) versus a comparison group at 12 months in two studies although differences were not statistically significant $[21,26]$. The active interventions in one of these studies decreased waist circumference by 1.6 to $2.4 \mathrm{~cm}$ at 12 months relative to standard written information $(P>0.05)$ [21]. 


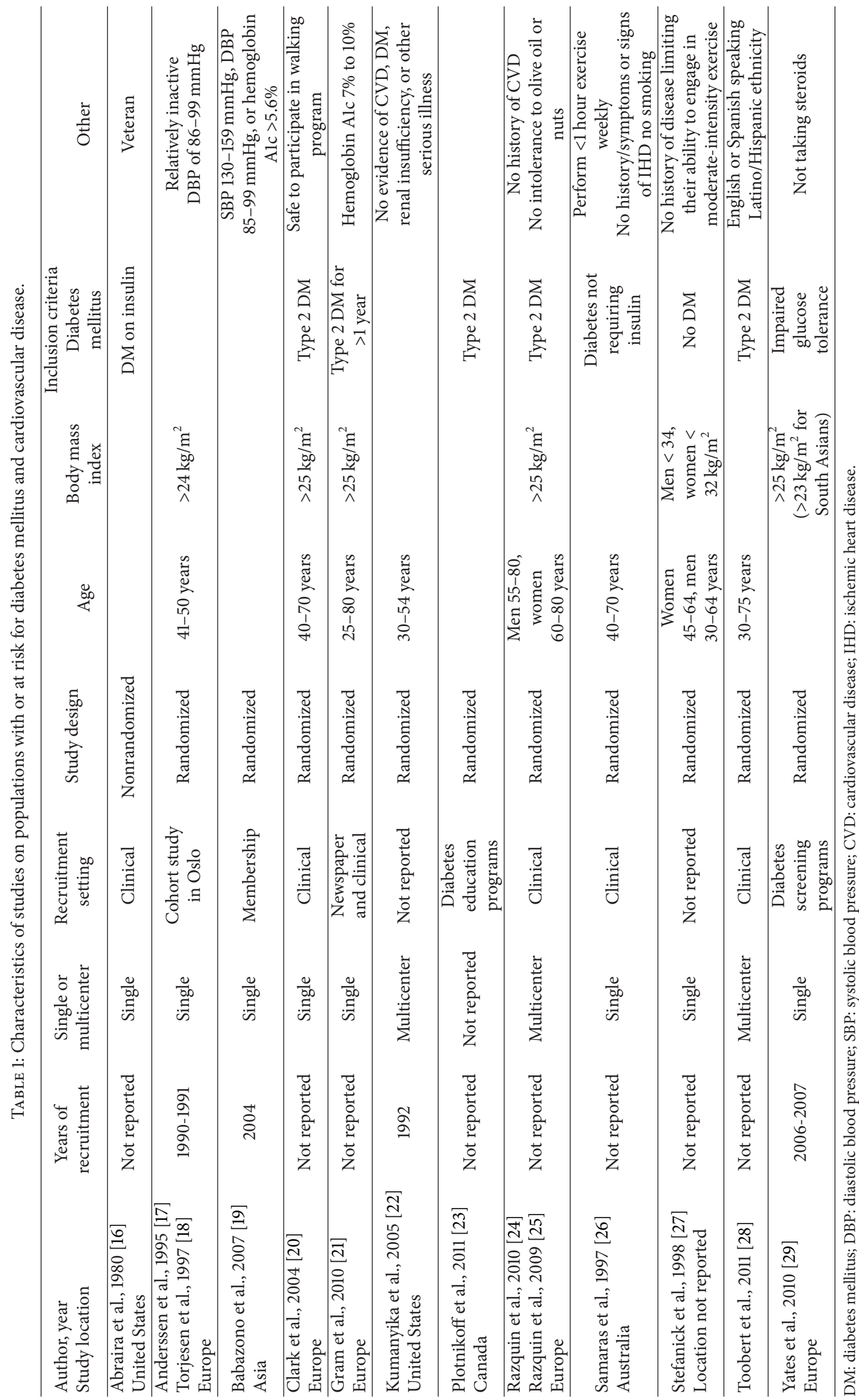




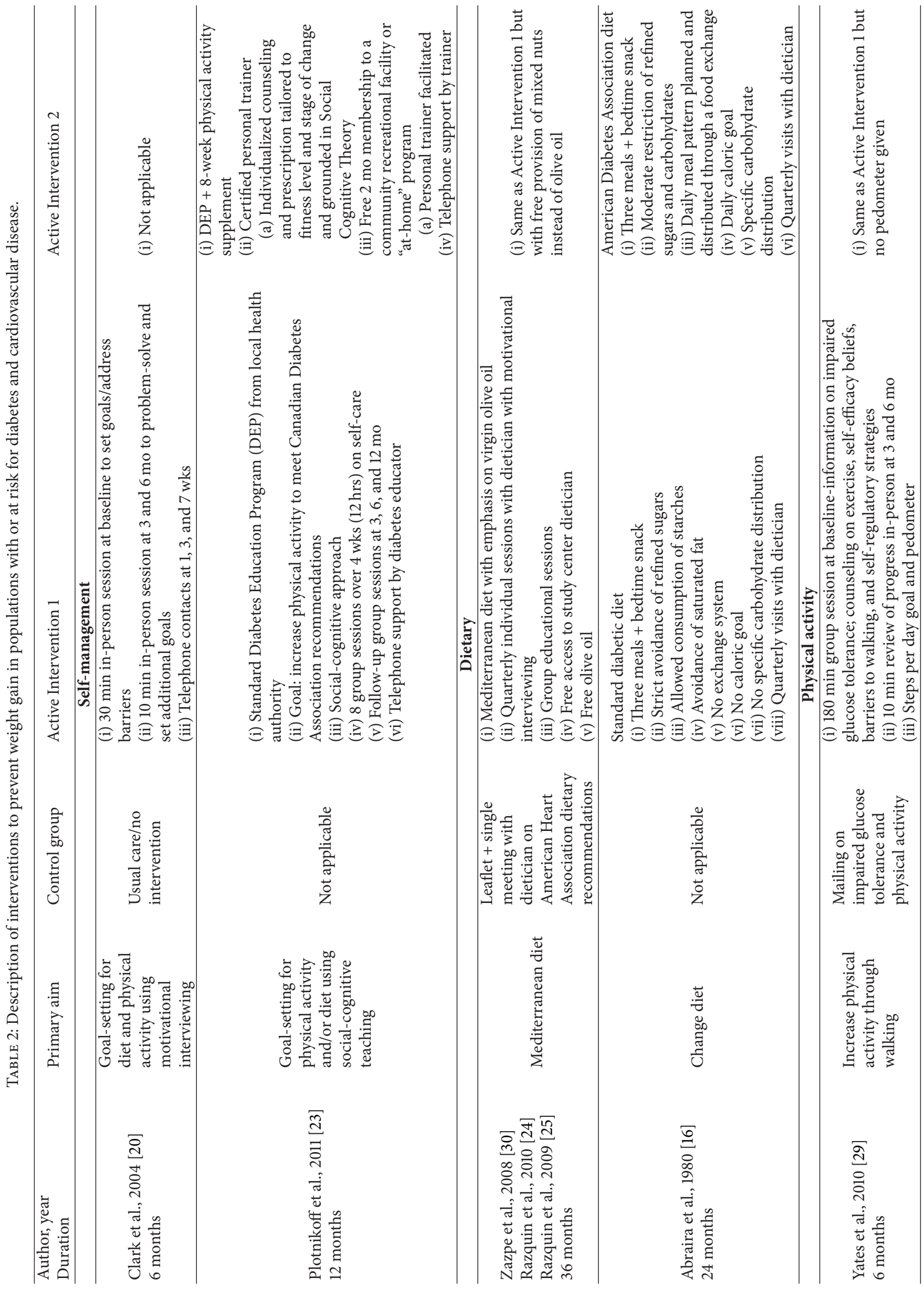




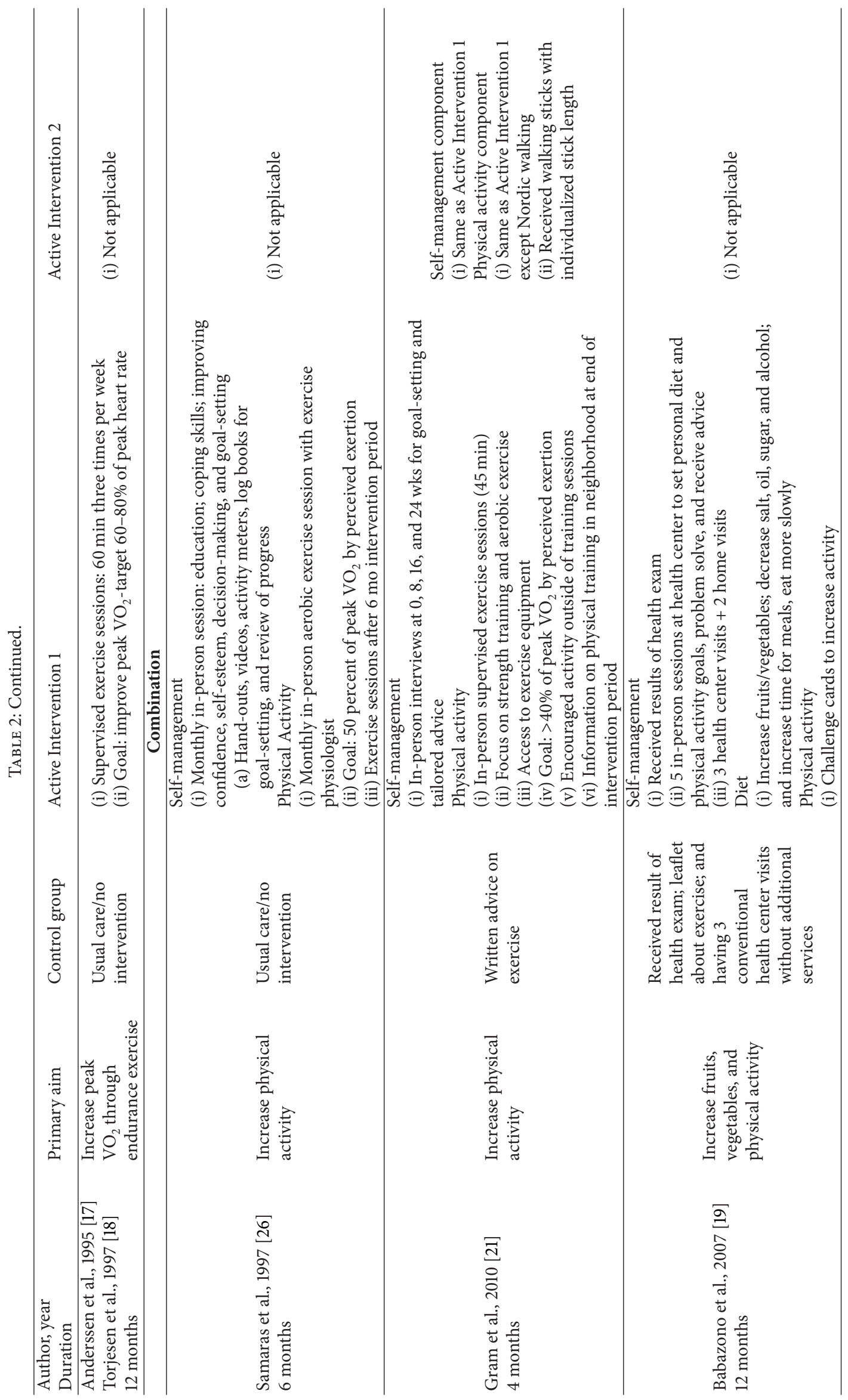




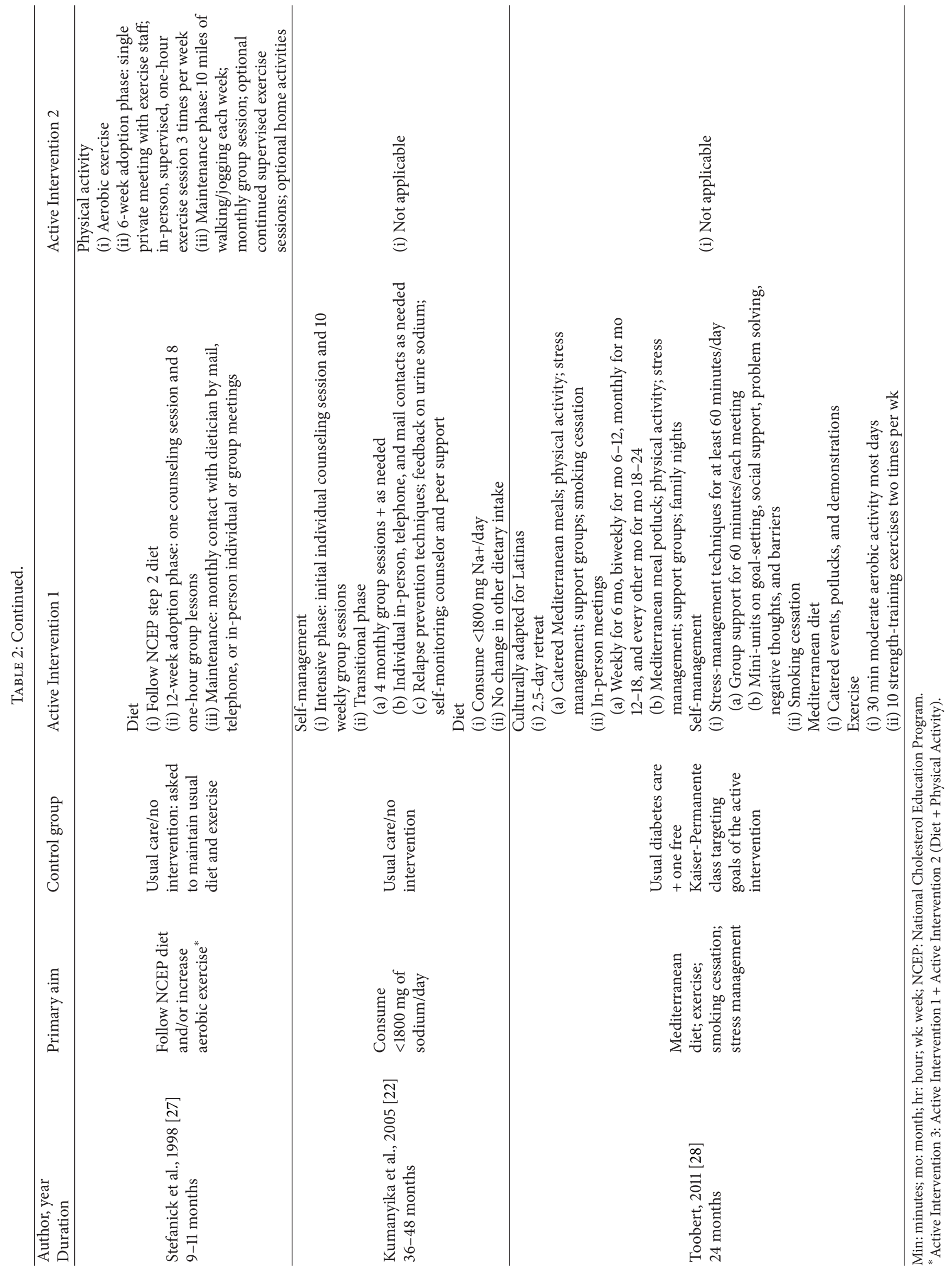




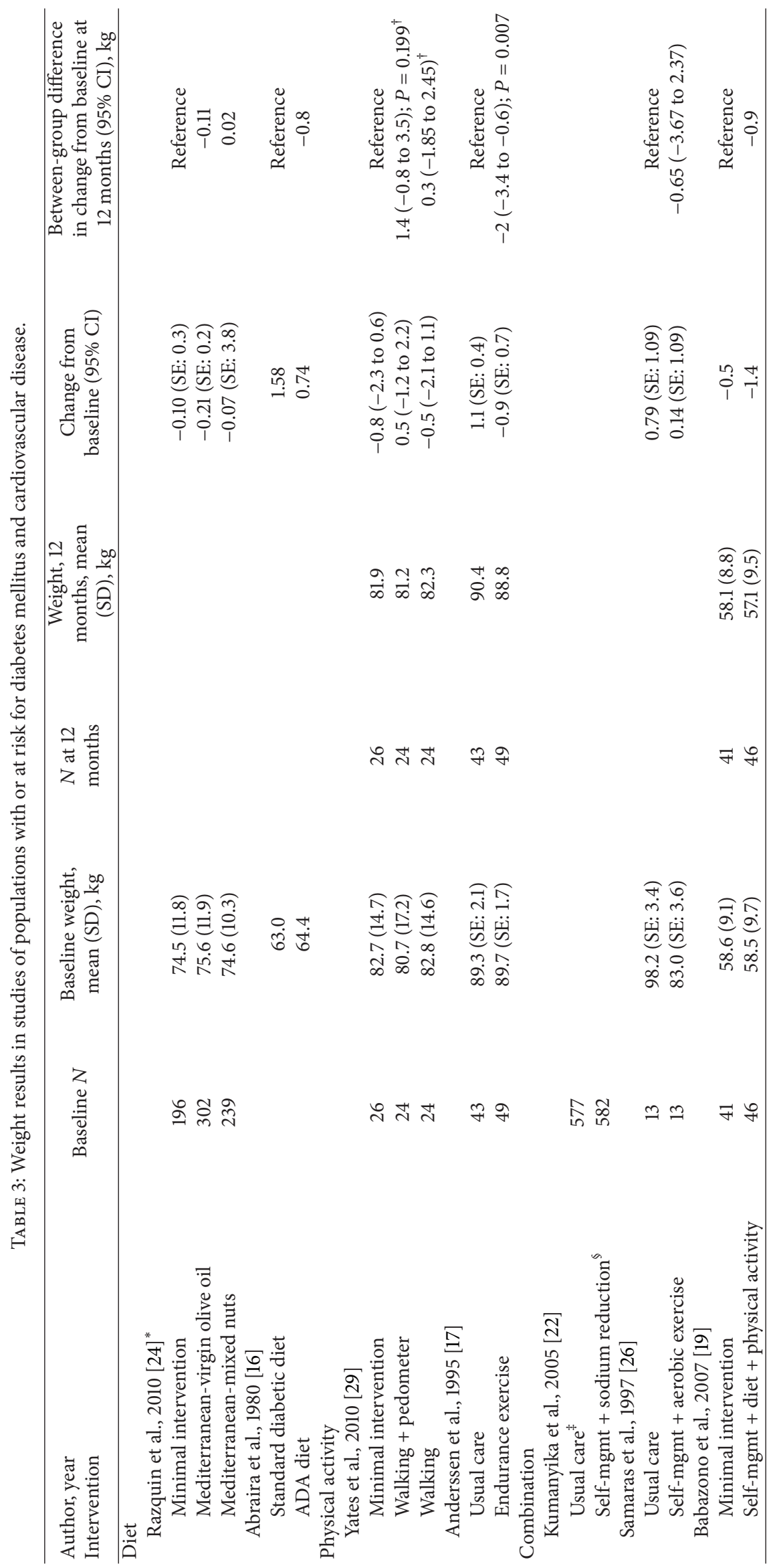




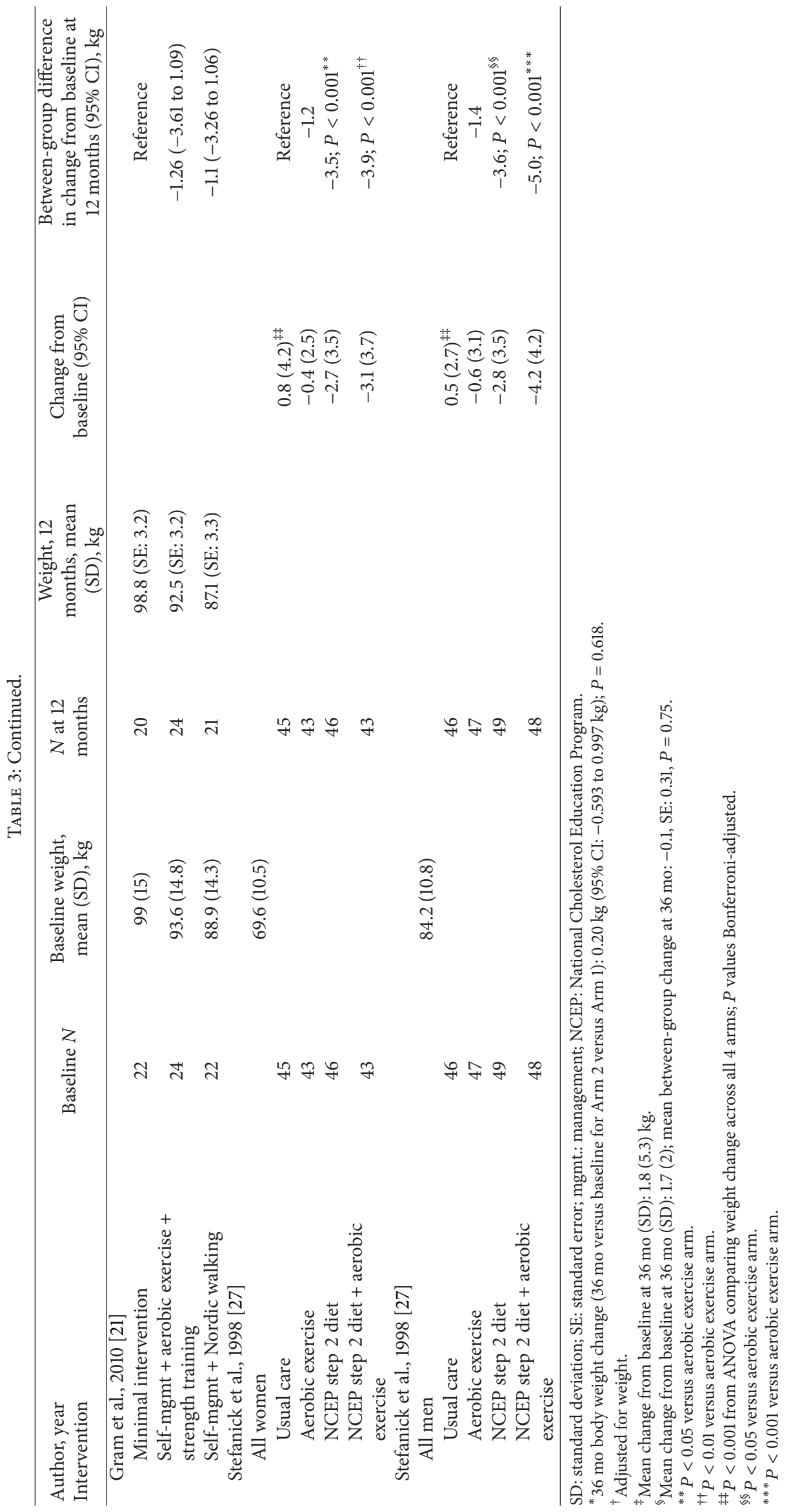




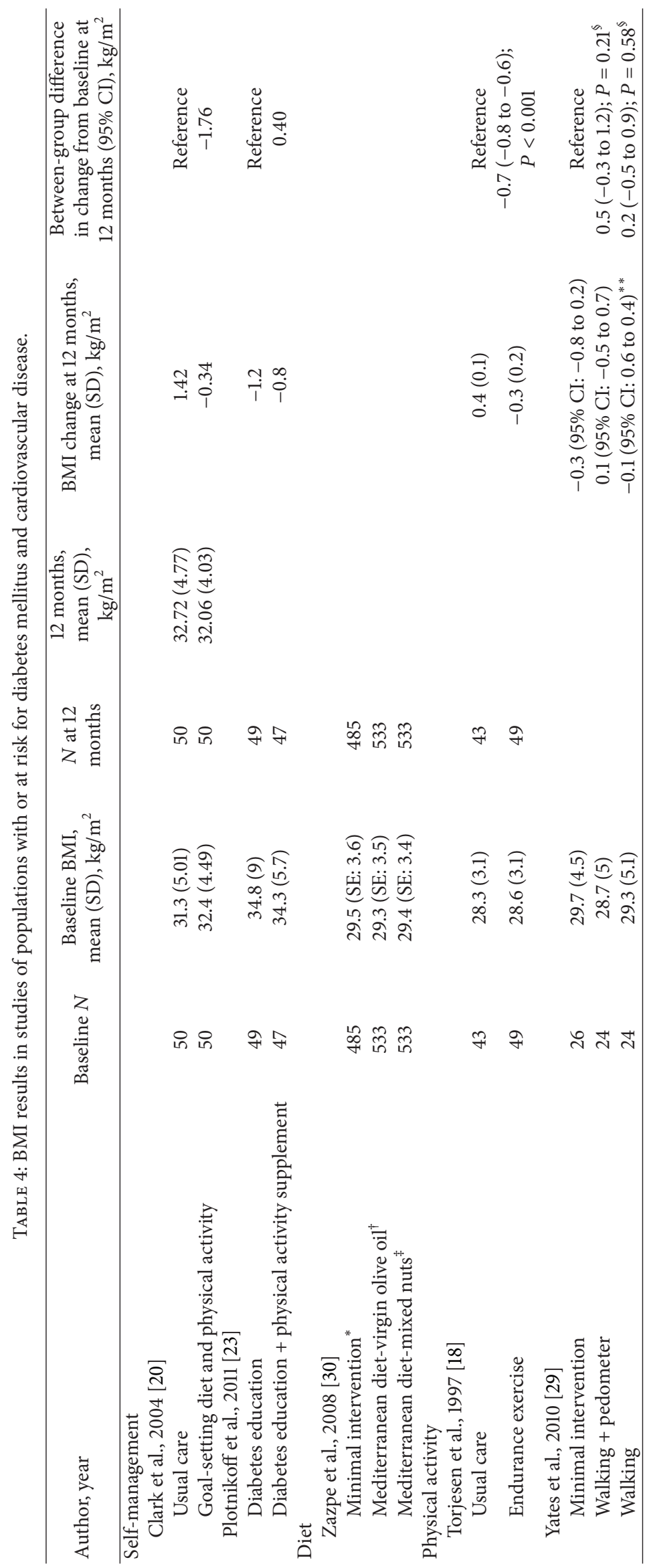




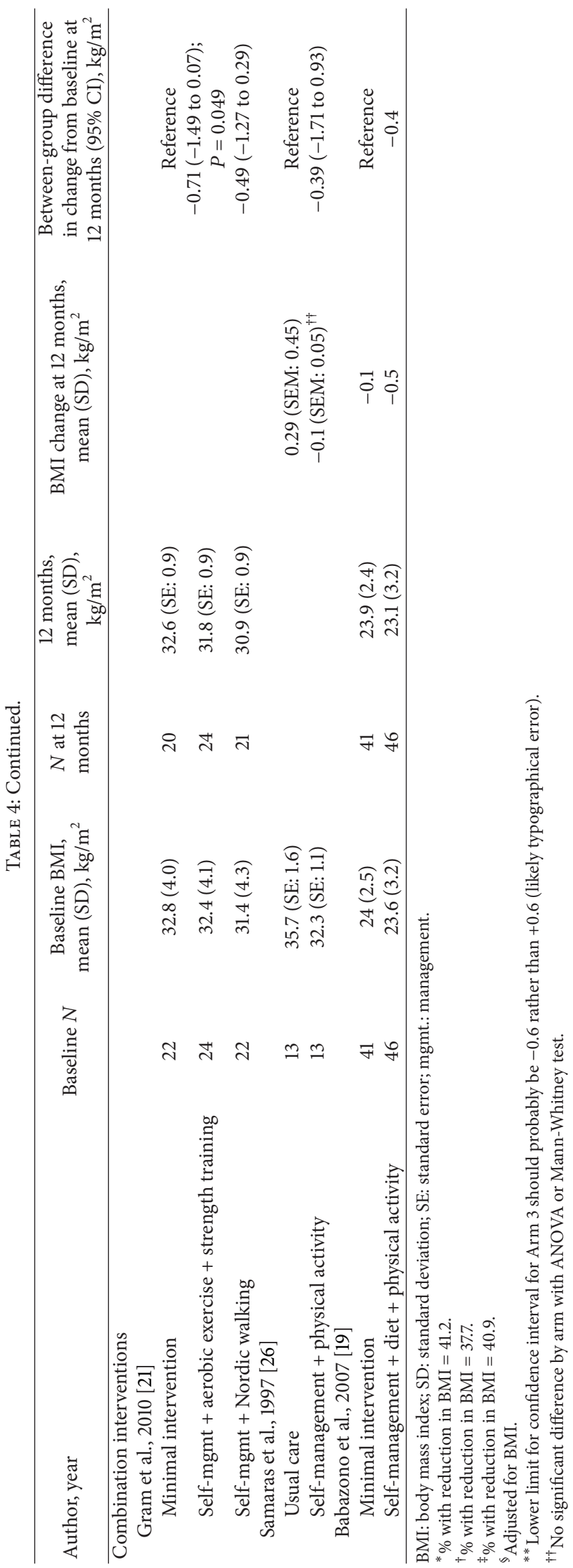




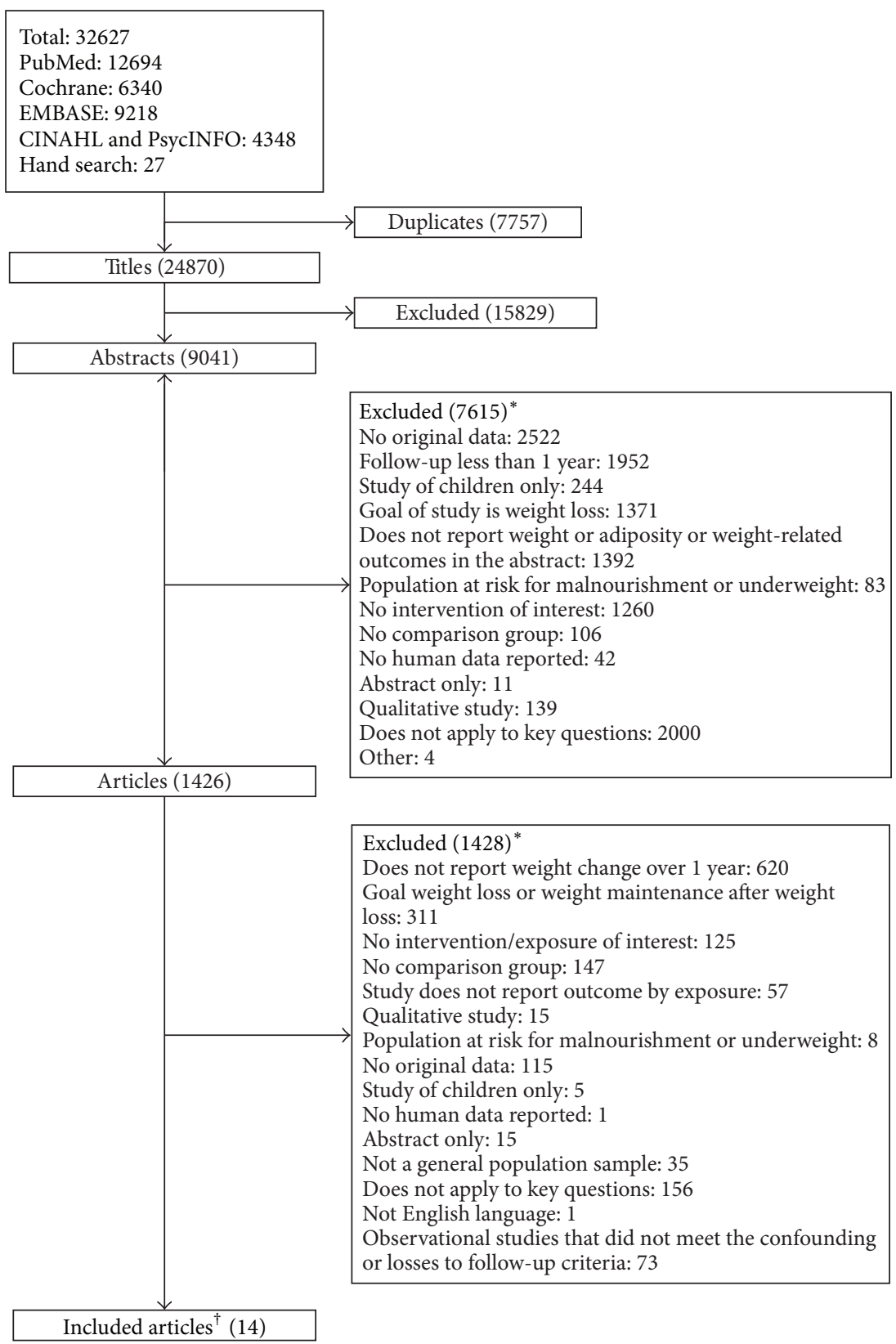

Figure 1: Selection of included studies. * Sum of reasons for exclusion of abstracts and articles exceeds total number of excluded abstracts and articles because reviewers were not required to agree on reasons for exclusion. ${ }^{\dagger}$ Fourteen articles of 12 individual studies included.

The combination of self-management, diet, and physical activity led to $0.9 \mathrm{~kg}$ more weight loss at 12 months which was not statistically significant compared with a minimal intervention in a single study [19]. Two trials comparing selfmanagement plus exercise and diet decreased BMI relative to a minimal intervention at 12 months (statistical significance not reported) $[19,28]$, but findings were not sustained at 24 months in the study evaluating this time point [28].

Modest weight gain occurred in both the active intervention arm combining sodium reduction and self-management and in the control arm at 36 months in the Trials of Hypertension (TOHP) II [22].
$H b A 1 c$. Four studies including patients with diabetes mellitus reported on $\mathrm{HbAlc}$ results and did not find significant effects of self-management or combination interventions on HbAlc relative to comparison arms at 12 months (Table S5, Figure S1) $[21,23,26,28]$.

Blood Pressure. The combination of self-management and sodium reduction decreased systolic blood pressure by $1.35 \mathrm{mmHg}(P=0.0165)$ and diastolic blood pressure by $0.61 \mathrm{mmHg}(P=0.16)$ relative to control at 36 months in the TOHP II [22]. Studies of self-management alone, physical activity alone, and other combination interventions for 


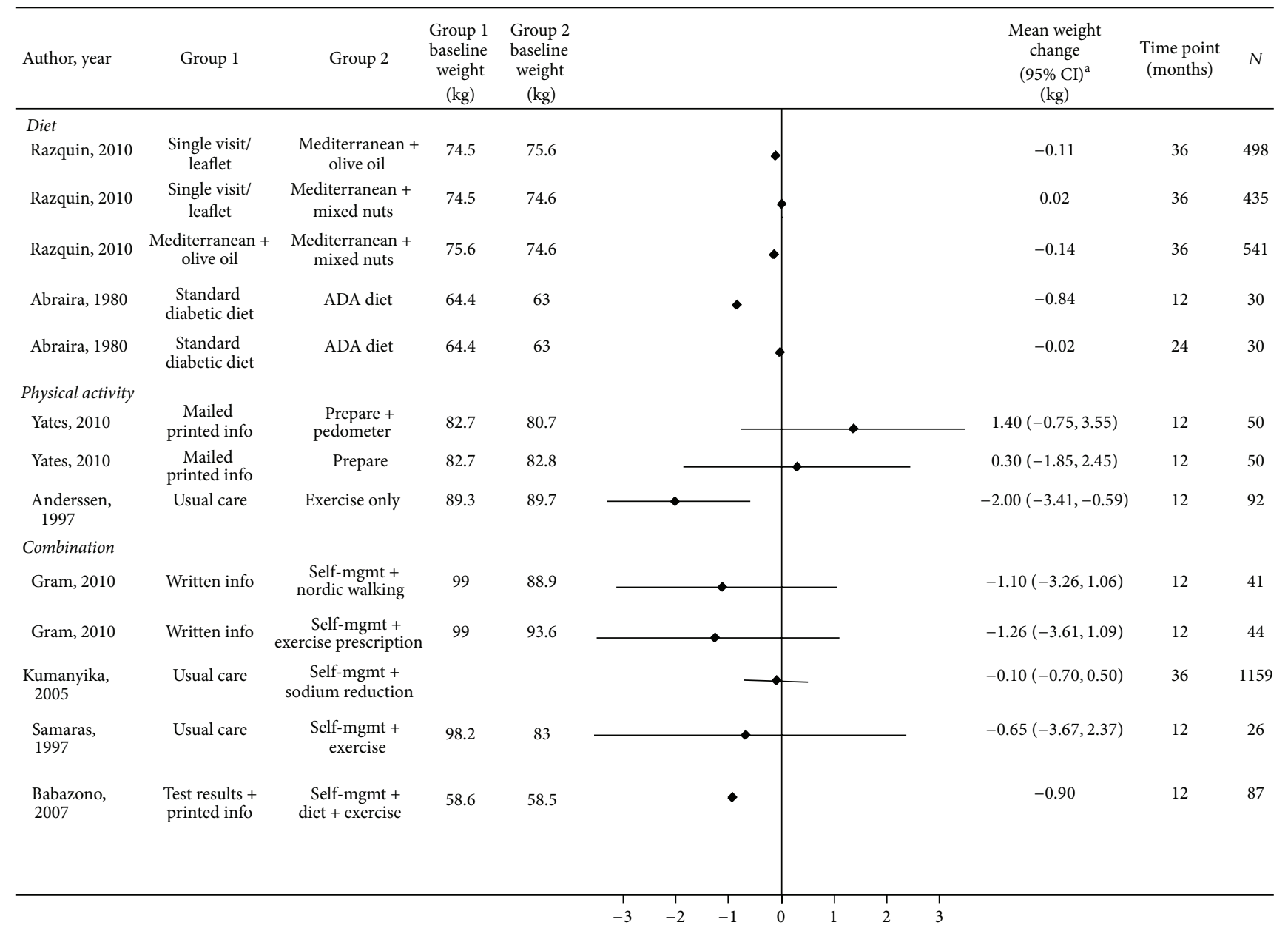

FIGURE 2: Effect of diet, physical activity, and combination interventions on weight change in participants with or at risk for cardiovascular disease and/or diabetes. ADA: American Diabetes Association; PREPARE: Prediabetes Risk Education and Physical Activity Recommendation and Encouragement. ${ }^{*} \mathrm{CI}$ is not provided if not reported and could not be calculated.

weight gain prevention either did not report on $[20,28]$ or did not significantly affect blood pressure (Table S6, Figures S2S3) $[17,19,21,23]$. Studies of diet interventions did not report on blood pressure $[16,30]$.

Cholesterol. Study results are provided in Table S7 and Figures S4-S5. Two active self-management interventions focusing on diabetes management and physical activity each increased HDL cholesterol and decreased LDL cholesterol at 12 months in one study [23]. Exercise interventions did not increase HDL at 12 months relative to comparison groups providing minimal or no intervention in the PREPARE or ODES $[17,29]$ and did not decrease LDL relative to control in ODES [17]. The combination of self-management and exercise decreased LDL at 12 months in a clinically meaningful but not statistically significant fashion relative to written information in one RCT (between-group difference range, -12 to $-16 \mathrm{mg} / \mathrm{dL}$ ) [21]. In this RCT, the arm incorporating Nordic walking decreased HDL by $6 \mathrm{mg} / \mathrm{dL}$ while the arm incorporating an exercise prescription increased HDL by $7 \mathrm{mg} / \mathrm{dL}$ relative to the comparison arm; between-group differences were not statistically significant [17]. Studies of dietary interventions did not report on cholesterol $[16,30]$.

Adherence. Adherence to endurance exercise three times per week was $57 \%$ over one year in ODES [17]. Adherence to a combination of self-management and physical activity interventions ranged from 64 to $100 \%$ [21, 26], and adherence to a combination of self-management, dietary, and physical activity was $46 \%$ in one RCT [28]. Trials of self-management and dietary interventions did not report on adherence.

\section{Discussion}

Among adults with or at risk for diabetes and CVD undergoing lifestyle interventions not focused on weight loss, we found that combining self-management and exercise prevented clinically significant increases in weight, BMI, and waist circumference as compared to control; however, none of these results were statistically significant. These interventions differentially included dietary components. We did not find consistent evidence that existing self-management, diet, or 


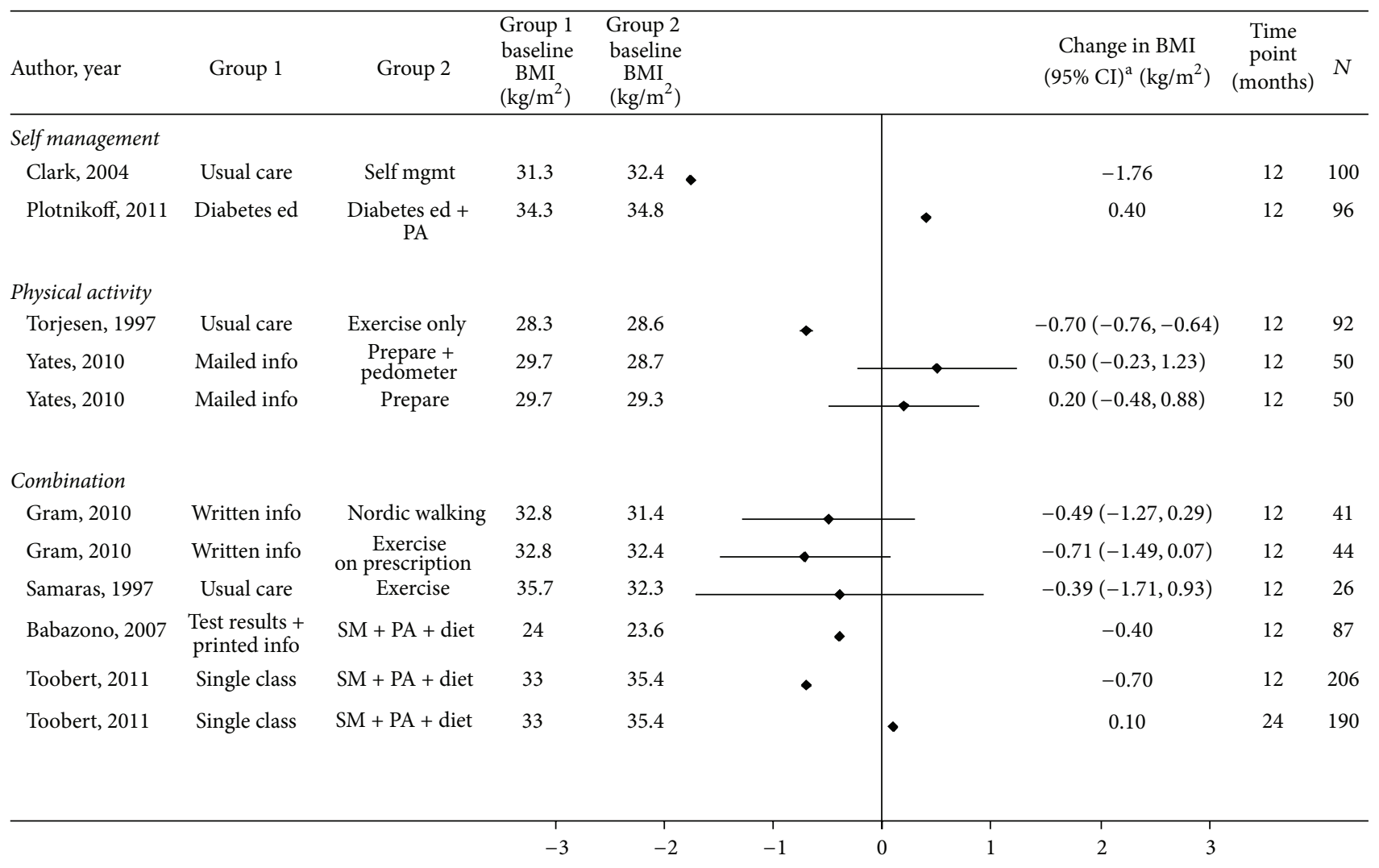

FIGURE 3: Effect of self-management, physical activity, and combination interventions on BMI change in participants with or at risk for cardiovascular disease and/or diabetes. Mgmt: management; ed: education; PA: physical activity; SM: self-management; PREPARE: Prediabetes Risk Education and Physical Activity Recommendation and Encouragement. ${ }^{*} \mathrm{CI}$ is not provided if not reported and could not be calculated.

physical activity interventions alone prevented increases in weight or BMI when studied relative to usual care or a minimal intervention; however, self-management and physical activity interventions in isolation prevented clinically meaningful, nonsignificant increases in waist circumference. None of the included studies led to a meaningful decrease in $\mathrm{HbAlc}$ or blood pressure relative to usual care; however, combining self-management and exercise lead to clinically meaningful, nonsignificant reductions in LDL. Overall, we found moderate-to-high risk of bias and low strength of evidence for weight-related outcomes in this study.

In the United States, adults gain on average one-half $\mathrm{kg}$ per year [14], related to a variety of factors that influence energy balance including overconsumption of calories and sedentary behavior, which are reinforced by both environmental and social factors. Many cardiometabolic diseases are negatively influenced by weight gain and obesity; paradoxically, many adults with cardiometabolic disease take prescriptions to manage these conditions that have been associated with weight gain. For example, sulfonylureas, thiazolidinediones, and insulin increase weight $[36,37]$, and betablockers are linked to weight gain [38]. This situation creates a clinical conundrum for providers who counsel their patients to avoid weight gain and yet may prescribe medications which cause just that. Therefore, better understanding what interventions are effective at preventing weight gain and/or maintaining weight among this high risk population is of critical importance.

In counseling patients on preventing weight gain, providers must consider how individual factors such as age, sex, obesity, and type 2 diabetes contribute to variation in the response to exercise and reduced caloric intake. Patients with diabetes undergoing an exercise intervention may not experience the beneficial physiologic changes in adipose tissue such as postexercise mobilization of fatty acids equivalent to that observed in lean, healthy individuals [39], which could explain the general lack of significant differences between active and minimal intervention arms on biochemical measurements such as blood pressure and HbAlc, especially in the absence of significant weight loss. A recent meta-analysis of RCTs in patients with type 2 diabetes did demonstrate the benefit of structured exercise on HbAlc which increased with the number of hours per week spent exercising [40]. The studies included in these meta-analyses were typically less than 12 months in duration and were not restricted to weight neutral interventions [40]. The weight neutral studies of exercise in patients with type 2 diabetes in our review were typically of lower intensity and were $>12$ months in duration. Similar to type 2 diabetes, obesity also modifies the response of adipose tissue to exercise [39]. 


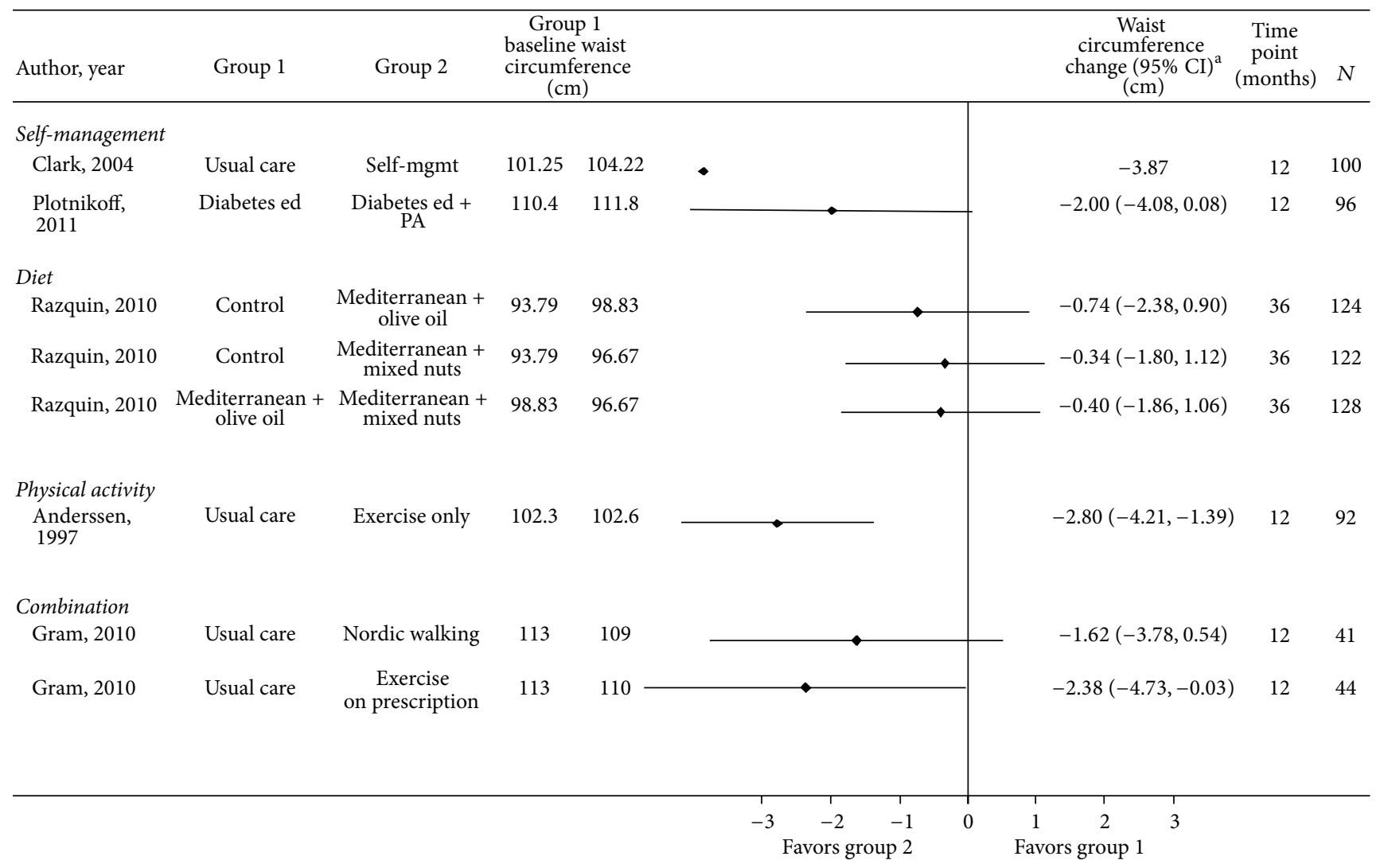

FIGURE 4: Effect of self-management, diet, physical activity, and combination interventions on waist circumference in participants with or at risk for cardiovascular disease and/or diabetes. Mgmt: management; ed: education; PA: physical activity. ${ }^{*} \mathrm{CI}$ is not provided if not reported and could not be calculated.

Insulin resistance is associated with a hyperadrenergic state [41] which may predispose to resistance to blood pressure reduction with lifestyle interventions. In total, patients with conditions placing them at higher risk for cardiometabolic disease may be in a state of metabolic disarray that attenuates their response to less-intensive physical activity and diet interventions such as those not focused on weight loss.

In this review, physical activity was an essential component of effective interventions with respect to weight gain prevention, weight maintenance, and LDL reduction. In theory, increased energy expenditure through physical activity with or without increases in fat-free mass should result in maintenance of body weight, if not weight loss. Resistance training exercise, as seen in two of the studies reviewed [19, 21], can increase fat-free mass and therefore increase energy expenditure [42]. This increased energy expenditure then facilitates weight gain prevention. Exercise can also reduce fat mass in proportion to the magnitude of the resulting energy deficit, but even substantial increases in physical activity may not cause enough of an energy deficit to result in weight loss [39]. However, exercise facilitates a small energy deficit that can result in weight or fat mass maintenance as observed in several of the included studies. This type of small energy deficit may preferentially reduce visceral fat depots $[39,43]$, which may lead to improved glycemic and lipid control for these patients independent of weight loss. We would encourage healthcare providers to counsel their patients with or at risk of cardiometabolic disease to regularly engage in both aerobic and resistance training exercise according to the current guidelines [44]. However, future research needs to confirm that the combination of self-management and exercise is the optimal strategy for preventing weight gain among these patients and elucidate specific details such as optimal duration and intensity, types of activities of most benefit, and subgroups (e.g., those with a higher versus lower BMI) which may benefit most.

We found moderate-to-high risk of bias for all main outcomes mainly because of a lack of masking of outcome assessors and other threats to internal validity and a lack of adequate reporting. We identified a total of 12 studies evaluating weight neutral lifestyle interventions in patients with or at risk for CVD and diabetes. Most of these studies were too small to find a statistically significant difference, and heterogeneity of interventions precluded quantitative synthesis of results across studies. Only one [16] of the 12 included studies stated that weight maintenance was the goal of the study. We included all studies meeting our inclusion criteria that did not explicitly state that weight loss was a goal of the study and by being inclusive, we may have included studies that actually targeted weight loss but just did not state 
this. This inclusion would be expected to bias our results toward showing a benefit of the interventions.

In this systematic review, experienced investigators conducted a thorough search of electronic databases and abstracted and synthesized data using a detailed protocol. Based on the extensive search, it is unlikely that we excluded important studies evaluating our interventions of interest. We are unaware of another systematic review evaluating weight-neutral lifestyle interventions in populations with or at risk for diabetes and/or CVD.

Adults tend to gain weight over time, and this, combined with difficulties translating weight loss interventions into clinical practice, makes the identification of interventions which help individuals avoid weight gain, especially in highrisk populations, paramount. In this systematic review, we found some evidence that the combination of self-management and exercise with or without diet may prevent weight gain or increases in BMI in patients with or at risk for diabetes and/or CVD, although the quality and strength of evidence were low. The downstream effect of these interventions on intermediate and clinical outcomes remains poorly studied. While the overall the evidence is insufficient to determine if weight neutral self-management, physical activity, and dietary interventions are worth pursuing at a population level, the available literature suggests that the combination of self-management and physical activity interventions holds the most promise. Given the lower intensity of interventions targeting avoidance of weight gain and the public health burden of weight gain in adulthood, we recommend future research on weight gain prevention interventions in patients with or at risk for diabetes and CVD to address the limitations of existing evidence and evaluate the impact of weight gain prevention interventions on intermediate and long-term clinical outcomes in these high-risk patients.

\section{Conflict of Interests}

The authors declare that there is no conflict of interests regarding the publication of this paper.

\section{Authors' Contribution}

Nisa M. Maruthur, Susan Hutfless, Kimberly Gudzune, Oluwakemi A. Fawole, Renee F. Wilson, Sara N. Bleich, Cheryl A. M. Anderson, Brandyn D. Lau, and Jodi Segal contributed to study design, literature search, and data interpretation. Nisa M. Maruthur, Susan Hutfless, Kimberly Gudzune, Oluwakemi A. Fawole, Renee F. Wilson, Sara N. Bleich, Brandyn D. Lau, and Jodi Segal contributed to data collection. Nisa M. Maruthur, Susan Hutfless, Oluwakemi A. Fawole, Renee F. Wilson, and Brandyn D. Lau generated tables and figures. Nisa M. Maruthur drafted the manuscript, had full access to all the data in the study, and takes responsibility for the integrity of the data and the accuracy of data analysis. All authors contributed to the revision of the paper and approved the submitted paper.

\section{Acknowledgments}

The authors thank Zoobia Chaudhry, MD (Johns Hopkins University, Baltimore, MD), for her contributions. Agency for Healthcare Research and Quality (AHRQ) Contract no. 2902007-10061-I from the AHRQ, U.S. Department of Health and Human Services (DHHS), supported the conduct of this systematic review. The authors of this report are responsible for its content. Statements in the report should not be construed as endorsement by the AHRQ or the DHHS. The funder has reviewed this paper.

\section{References}

[1] E. S. Ford and R. S. Cooper, "Risk factors for hypertension in a national cohort study," Hypertension, vol. 18, no. 5, pp. 598-606, 1991.

[2] G. Reaven, "Insulin resistance and coronary heart disease in nondiabetic individuals," Arteriosclerosis, Thrombosis, and Vascular Biology, vol. 32, no. 8, pp. 1754-1759, 2012.

[3] S. N. Blair, N. N. Goodyear, L. W. Gibbons, and K. H. Cooper, "Physical fitness and incidence of hypertension in healthy normotensive men and women," Journal of the American Medical Association, vol. 252, no. 4, pp. 487-490, 1984.

[4] "Relationship between baseline risk factors and coronary heart disease and total mortality in the Multiple Risk Factor Intervention Trial," Preventive Medicine, vol. 15, pp. 254-273, 1986.

[5] E. B. Rimm, M. J. Stampfer, E. Giovannucci et al., "Body size and fat distribution as predictors of coronary heart disease among middle-aged and older US men," American Journal of Epidemiology, vol. 141, no. 12, pp. 1117-1127, 1995.

[6] J. Stamler, R. Stamler, and J. D. Neaton, "Blood pressure, systolic and diastolic, and cardiovascular risks: US population data," Archives of Internal Medicine, vol. 153, no. 5, pp. 598-615, 1993.

[7] F. B. Hu, J. E. Manson, M. J. Stampfer et al., "Diet, lifestyle, and the risk of type 2 diabetes mellitus in women," The New England Journal of Medicine, vol. 345, no. 11, pp. 790-797, 2001.

[8] "Standards of medical care in diabetes-2012," Diabetes Care, vol. 35, supplement 1, pp. S11-S63, 2012.

[9] Diabetes Prevention Program Research Group, "Reduction in the incidence of type 2 diabetes with lifestyle intervention or metformin," The New England Journal of Medicine, vol. 346, pp. 393-403, 2002.

[10] L. J. Appel, C. M. Champagne, D. W. Harsha et al., "Effects of comprehensive lifestyle modification on blood pressure control: main results of the PREMIER clinical trial," Journal of the American Medical Association, vol. 289, no. 16, pp. 2083-2093, 2003.

[11] L. P. Svetkey, V. J. Stevens, P. J. Brantley et al., "Comparison of strategies for sustaining weight loss: the weight loss maintenance randomized controlled trial," The Journal of the American Medical Association, vol. 299, no. 10, pp. 1139-1148, 2008.

[12] N. M. Maruthur, N.-Y. Wang, and L. J. Appel, "Lifestyle interventions reduce coronary heart disease risk: results from the premier trial," Circulation, vol. 119, no. 15, pp. 2026-2031, 2009.

[13] S. T. Chen, N. M. Maruthur, and L. J. Appel, "The effect of dietary patterns on estimated coronary heart disease risk results from the Dietary Approaches to Stop Hypertension (DASH) trial," Circulation: Cardiovascular Quality and Outcomes, vol. 3, no. 5, pp. 484-489, 2010. 
[14] K. D. Hall, G. Sacks, D. Chandramohan et al., "Quantification of the effect of energy imbalance on bodyweight," The Lancet, vol. 378, no. 9793, pp. 826-837, 2011.

[15] S. Hutfless, N. M. Maruthur, R. F. Wilson et al., Strategies to Prevent Weight Gain Among Adults. Comparative Effectiveness Review No. 97, Agency for Healthcare Research and Quality, Rockville, Md, USA, 2013.

[16] C. Abraira, M. de Bartolo, and J. W. Myscofski, "Comparison of unmeasured versus exchange diabetic diets in lean adults. Body weight and feeding patterns in a 2-year prospective pilot study," The American Journal of Clinical Nutrition, vol. 33, no. 5, pp. 1064-1070, 1980.

[17] S. A. Anderssen, A. Haaland, I. Hjermann, P. Urdal, K. Gjesdal, and I. Holme, "Oslo Diet and Exercise Study: a one-year randomized intervention trial. Effect on hemostatic variables and other coronary risk factors," Nutrition, Metabolism and Cardiovascular Diseases, vol. 5, pp. 189-200, 1995.

[18] P. A. Torjesen, K. I. Birkeland, S. A. Anderssen, I. Hjermann, I. Holme, and P. Urdal, "Lifestyle changes may reverse development of the insulin resistance syndrome: the Oslo Diet and Exercise Study: a randomized trial," Diabetes Care, vol. 20, no. 1, pp. 26-31, 1997.

[19] A. Babazono, C. Kame, R. Ishihara, E. Yamamoto, and A. L. Hillman, "Patient-motivated prevention of lifestyle-related disease in Japan," Disease Management and Health Outcomes, vol. 15, no. 2, pp. 119-126, 2007.

[20] M. Clark, S. E. Hampson, L. Avery, and R. Simpson, "Effects of a tailored lifestyle self-management intervention in patients with Type 2 diabetes," British Journal of Health Psychology, vol. 9, no. 3, pp. 365-379, 2004.

[21] B. Gram, R. Christensen, C. Christiansen, and J. Gram, "Effects of Nordic walking and exercise in type 2 diabetes mellitus: a randomized controlled trial," Clinical Journal of Sport Medicine, vol. 20, no. 5, pp. 355-361, 2010.

[22] S. K. Kumanyika, N. R. Cook, J. A. Cutler et al., "Sodium reduction for hypertension prevention in overweight adults: further results from the Trials of Hypertension Prevention Phase II," Journal of Human Hypertension, vol. 19, no. 1, pp. 33-45, 2005.

[23] R. C. Plotnikoff, M. A. Pickering, N. Glenn et al., "The effects of a supplemental, theory-based physical activity counseling intervention for adults with type 2 diabetes," Journal of Physical Activity and Health, vol. 8, no. 7, pp. 944-954, 2011.

[24] C. Razquin, J. A. Martinez, M. A. Martinez-Gonzalez, J. Fernández-Crehuet, J. M. Santos, and A. Marti, "A Mediterranean diet rich in virgin olive oil may reverse the effects of the -174G/C IL6 gene variant on 3-year body weight change," Molecular Nutrition and Food Research, vol. 54, supplement 1, pp. S75-S82, 2010.

[25] C. Razquin, J. A. Martinez, M. A. Martinez-Gonzalez, M. T. Mitjavila, R. Estruch, and A. Marti, "A 3 years follow-up of a Mediterranean diet rich in virgin olive oil is associated with high plasma antioxidant capacity and reduced body weight gain," European Journal of Clinical Nutrition, vol. 63, no. 12, pp. 13871393, 2009.

[26] K. Samaras, S. Ashwell, A.-M. Mackintosh, A. C. Fleury, L. V. Campbell, and D. J. Chisholm, "Will older sedentary people with non-insulin-dependent diabetes mellitus start exercising? A health promotion model," Diabetes Research and Clinical Practice, vol. 37, no. 2, pp. 121-128, 1997.

[27] M. L. Stefanick, S. Mackey, M. Sheehan, N. Ellsworth, W. L. Haskell, and P. D. Wood, "Effects of diet and exercise in men and postmenopausal women with low levels of HDL cholesterol and high levels of LDL cholesterol," The New England Journal of Medicine, vol. 339, no. 1, pp. 12-20, 1998.

[28] D. J. Toobert, L. A. Strycker, D. K. King, M. Barrera Jr., D. Osuna, and R. E. Glasgow, "Long-term outcomes from a multiplerisk-factor diabetes trial for Latinas: ¡Viva Bien!”, Translational Behavioral Medicine, vol. 1, no. 3, pp. 416-426, 2011.

[29] T. Yates, M. J. Davies, T. Gorely et al., "The effect of increased ambulatory activity on markers of chronic low-grade inflammation: evidence from the PREPARE programme randomized controlled trial," Diabetic Medicine, vol. 27, no. 11, pp. 1256-1263, 2010.

[30] I. Zazpe, A. Sanchez-Tainta, R. Estruch et al., "A large randomized individual and group intervention conducted by registered dietitians increased adherence to Mediterranean-type diets: the PREDIMED Study," Journal of the American Dietetic Association, vol. 108, no. 7, pp. 1134-1144, 2008.

[31] S. H. Downs and N. Black, "The feasibility of creating a checklist for the assessment of the methodological quality both of randomised and non-randomised studies of health care interventions," Journal of Epidemiology and Community Health, vol. 52, no. 6, pp. 377-384, 1998.

[32] D. K. Owens, K. N. Lohr, D. Atkins et al., "AHRQ Series Paper 5: Grading the strength of a body of evidence when comparing medical interventions-Agency for Healthcare Research and Quality and the Effective Health-Care Program," Journal of Clinical Epidemiology, vol. 63, no. 5, pp. 513-523, 2010.

[33] D. Romaguera, L. Ängquist, H. Du et al., "Dietary determinants of changes in waist circumference adjusted for body mass index-a proxy measure of visceral adiposity," PLoS ONE, vol. 5, no. 7, Article ID el1588, 2010.

[34] X. Pi-Sunyer, G. Blackburn, F. L. Brancati et al., "Reduction in weight and cardiovascular disease risk factors in individuals with type 2 diabetes: one-year results of the Look AHEADtrial," Diabetes Care, vol. 30, no. 6, pp. 1374-1383, 2007.

[35] H. I. Katcher, A. M. Hill, J. L. G. Lanford, J. S. Yoo, and P. M. KrisEtherton, "Lifestyle approaches and dietary strategies to lower LDL-cholesterol and triglycerides and raise HDL-cholesterol," Endocrinology and Metabolism Clinics of North America, vol. 38, no. 1, pp. 45-78, 2009.

[36] W. L. Bennett, N. M. Maruthur, S. Singh et al., "Comparative effectiveness and safety of medications for type 2 diabetes: an update including new drugs and 2-drug combinations," Annals of Internal Medicine, vol. 154, no. 9, pp. 602-618, 2011.

[37] A. E. Pontiroli, L. Miele, and A. Morabito, "Increase of body weight during the first year of intensive insulin treatment in type 2 diabetes: systematic review and meta-analysis," Diabetes, Obesity and Metabolism, vol. 13, no. 11, pp. 1008-1019, 2011.

[38] F. H. Messerli, D. S. H. Bell, V. Fonseca et al., "Body weight changes with $\beta$-blocker use: results from Gemini," The American Journal of Medicine, vol. 120, no. 7, pp. 610-615, 2007.

[39] D. Thompson, F. Karpe, M. Lafontan, and K. Frayn, "Physical activity and exercise in the regulation of human adipose tissue physiology," Physiological Reviews, vol. 92, no. 1, pp. 157-191, 2012.

[40] D. Umpierre, P. A. B. Ribeiro, C. K. Kramer et al., "Physical activity advice only or structured exercise training and association with HbAlc levels in type 2 diabetes: a systematic review and meta-analysis," The Journal of the American Medical Association, vol. 305, no. 17, pp. 1790-1799, 2011.

[41] G. Grassi, "Sympathetic neural activity in hypertension and related diseases," American Journal of Hypertension, vol. 23, no. 10, pp. 1052-1060, 2010. 
[42] C. Weyer, S. Snitker, R. Rising, C. Bogardus, and E. Ravussin, "Determinants of energy expenditure and fuel utilization in man: effects of body composition, age, sex, ethnicity and glucose tolerance in 916 subjects," International Journal of Obesity, vol. 23, no. 7, pp. 715-722, 1999.

[43] E. Ravussin, S. Lillioja, T. E. Anderson, L. Christin, and C. Bogardus, "Determinants of 24-hour energy expenditure in man. Methods and results using a respiratory chamber," Journal of Clinical Investigation, vol. 78, no. 6, pp. 1568-1578, 1986.

[44] U.S. Department of Health and Human Services, 2008 Physical Activity Guidelines for Americans, 2008. 


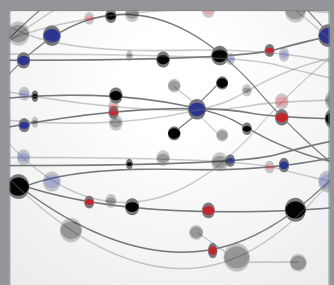

The Scientific World Journal
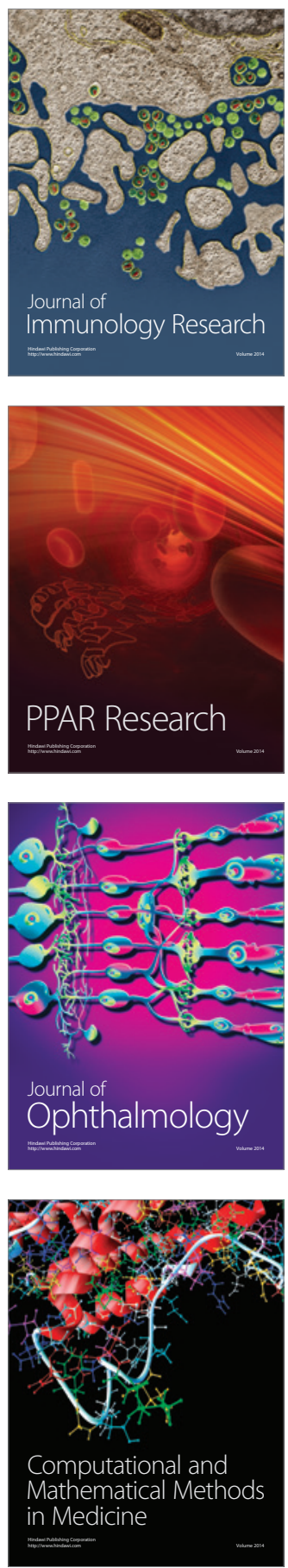

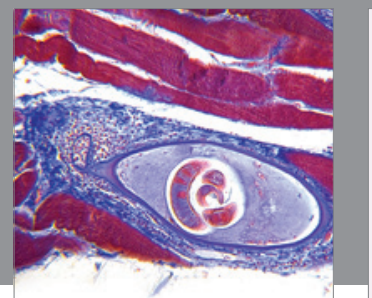

Gastroenterology

Research and Practice
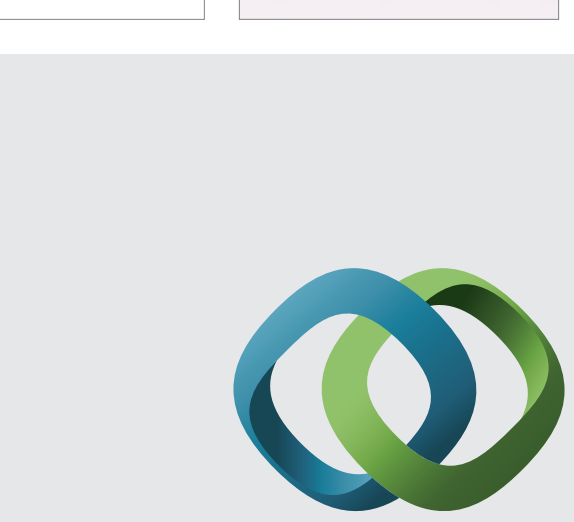

\section{Hindawi}

Submit your manuscripts at

http://www.hindawi.com
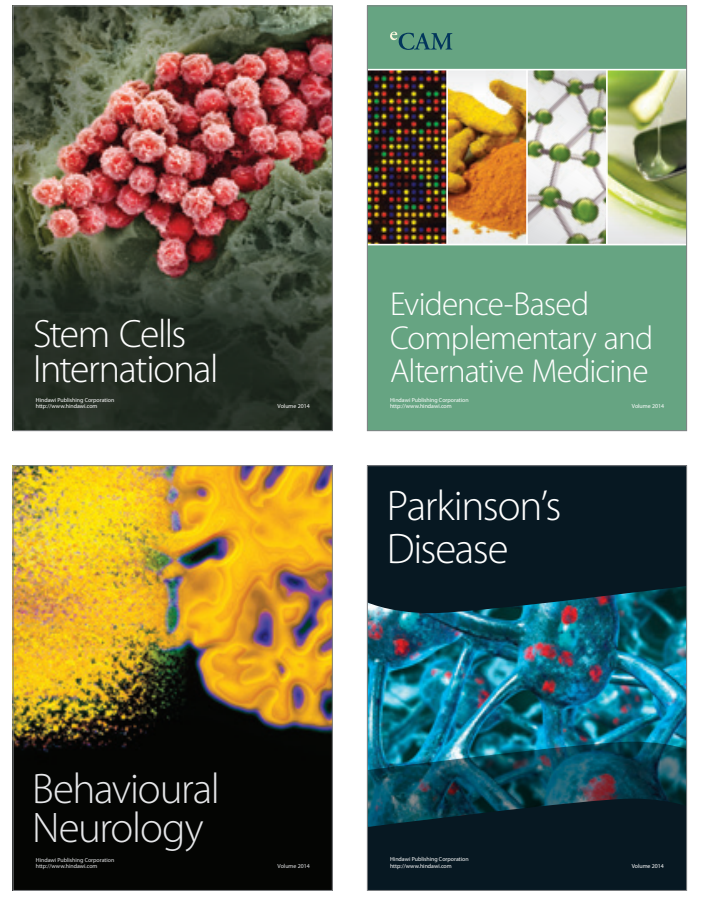
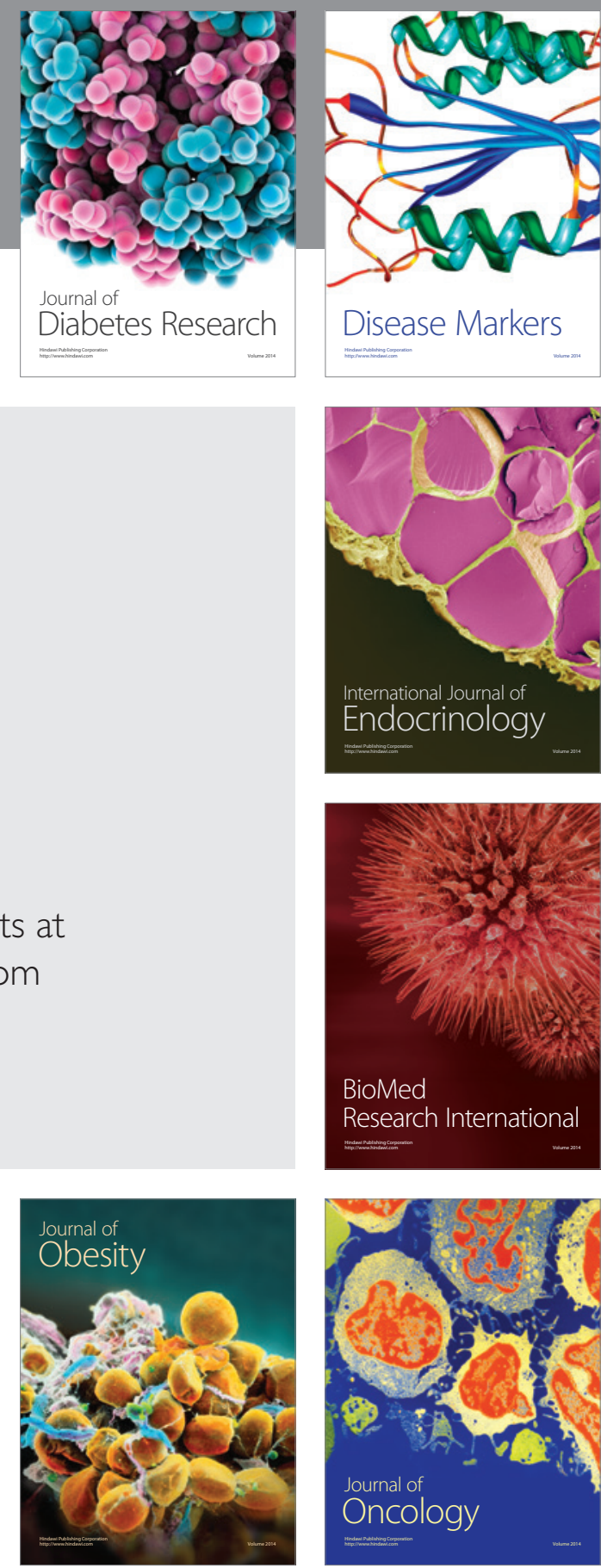

Disease Markers
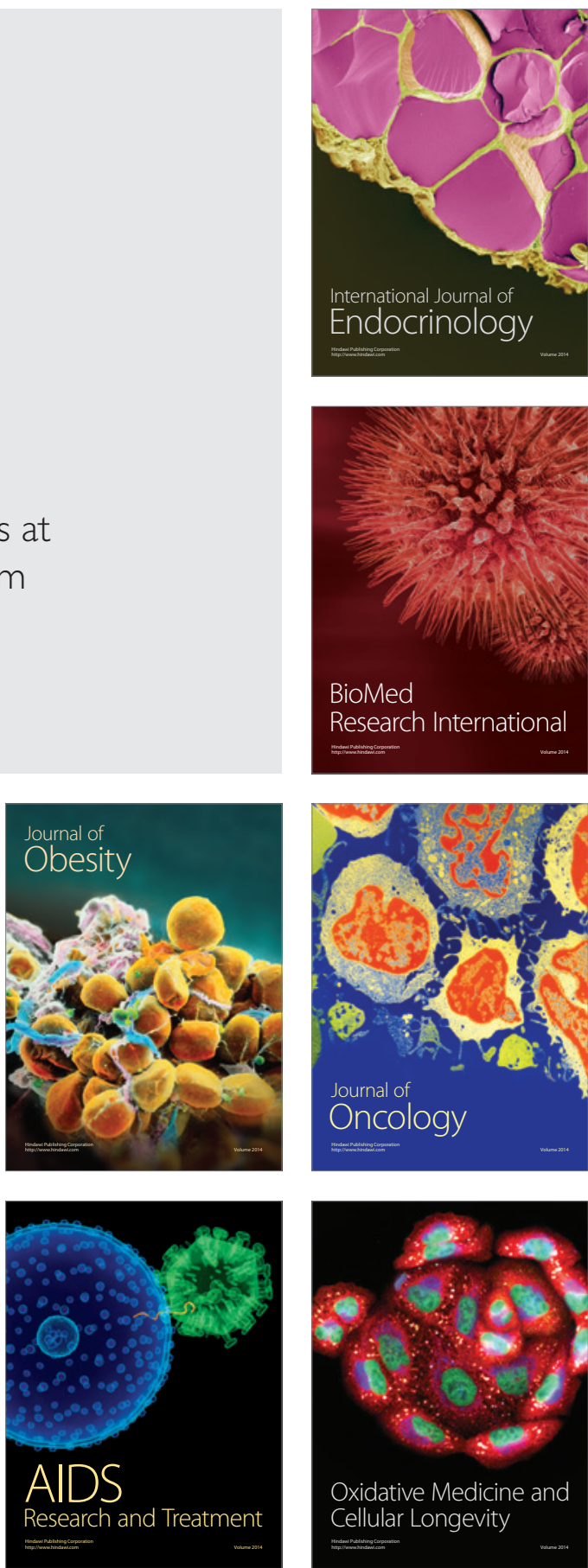